\title{
Thermochromic Multicolored Photonic Coatings with Light Polarization- and Structural Color-Dependent Changes
}

\section{Citation for published version (APA):}

Zhang, W., Schenning, A. P. H. J., Kragt, A. J. J., Zhou, G., \& de Haan, L. T. (2022). Thermochromic Multicolored Photonic Coatings with Light Polarization- and Structural Color-Dependent Changes. ACS Applied Polymer Materials, 4(1), 537-545. https://doi.org/10.1021/acsapm.1c01434

\section{Document license:}

CC BY-NC-ND

DOI:

10.1021/acsapm.1c01434

Document status and date:

Published: 14/01/2022

\section{Document Version:}

Publisher's PDF, also known as Version of Record (includes final page, issue and volume numbers)

\section{Please check the document version of this publication:}

- A submitted manuscript is the version of the article upon submission and before peer-review. There can be important differences between the submitted version and the official published version of record. People interested in the research are advised to contact the author for the final version of the publication, or visit the $\mathrm{DOI}$ to the publisher's website.

- The final author version and the galley proof are versions of the publication after peer review.

- The final published version features the final layout of the paper including the volume, issue and page numbers.

Link to publication

\section{General rights}

Copyright and moral rights for the publications made accessible in the public portal are retained by the authors and/or other copyright owners and it is a condition of accessing publications that users recognise and abide by the legal requirements associated with these rights.

- Users may download and print one copy of any publication from the public portal for the purpose of private study or research.

- You may not further distribute the material or use it for any profit-making activity or commercial gain

- You may freely distribute the URL identifying the publication in the public portal.

If the publication is distributed under the terms of Article 25fa of the Dutch Copyright Act, indicated by the "Taverne" license above, please follow below link for the End User Agreement:

www.tue.nl/taverne

Take down policy

If you believe that this document breaches copyright please contact us at:

openaccess@tue.nl

providing details and we will investigate your claim. 


\title{
Thermochromic Multicolored Photonic Coatings with Light Polarization- and Structural Color-Dependent Changes
}

\author{
Weixin Zhang, Albertus P.H.J. Schenning, Augustinus J.J. Kragt, Guofu Zhou,* and Laurens T. de Haan*
}

Cite This: ACS Appl. Polym. Mater. 2022, 4, 537-545

Read Online
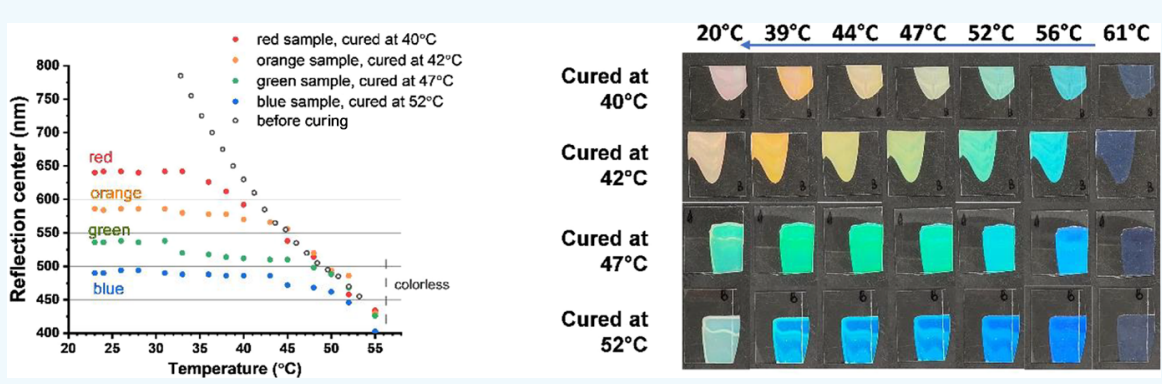

ABSTRACT: Both temperature-responsive and patterned photonic coatings are receiving a lot of attention from a fundamental and application point of view. However, the fabrication of multicolor patterns, which are also temperature-responsive, remains challenging. The current work presents a thermochromic photonic coating with light polarization-dependent multiple structural colors from a polymer-stabilized cholesteric liquid crystal siloxane oligomer. It is found that the structural color and the temperature response can be manipulated by varying the polymerization temperature, allowing the fabrication of thermochromic multicolor patterns. During heating, each color starts shifting at a different temperature until the sample is entirely blue at a high temperature. Upon cooling, the multicolor pattern returns, showing that the thermochromic response is reversible. On top of that, linearly polarized light dependency is also obtained, showing different reflection colors when varying the incident light polarization angles. A multicolor, thermochromic photonic coating with light polarization- and structural color-dependent features is fabricated for demonstration.

KEYWORDS: cholesteric liquid crystals, thermochromic, linearly polarized light, photonic structures, 3D helical structures, patterning

\section{INTRODUCTION}

Photonic structures that present selective reflection colors based on alternating refractive indices inside the material are widely found in nature. ${ }^{1,2}$ Multicolor patterns ${ }^{3-5}$ as well as light polarization-dependent color $^{6,7}$ are present in many species. Dynamic photonic structures are also found, like chameleons adapting their skin color to the environment for camouflage and body temperature control. ${ }^{8}$ Inspired by nature, research on artificial photonic structures ${ }^{9-12}$ is dedicated to creating colorful patterns $^{12-19}$ as well as thermochromism ${ }^{9,20}$ and light polarization-dependent colors. ${ }^{21-23}$ Such materials are interesting for applications ranging from temperature control in buildings to security features. However, a photonic material combining all these features has not been realized yet.

Cholesteric liquid crystals (ChLCs) are a popular photonic material for fabricating temperature-responsive devices. ${ }^{24-26}$ The nanostructure of ChLCs is helicoidal, organized by the rotation of the anisotropic liquid crystal moieties giving rise to their structural color. The reflection wavelength $(\lambda)$ of the structural color is a function of the rotational pitch length $(p)$ of the helical structure. Molecular design of ChLC materials allows for $p$ to be responsive to temperature through various mechanisms, with a corresponding shift of the reflection band. $^{24}$ ChLC materials can be obtained by industrially feasible coating processes, such as bar coating and printing. Temperature-responsive ChLC coatings have been fabricated with versatile processabilities, ${ }^{27-31}$ a wide color tuning range, $^{31-33}$ variable working temperatures, ${ }^{34,35}$ controllable response speed, ${ }^{36-38}$ reversibility, ${ }^{39,40}$ and good stability. ${ }^{38,41,42}$ Patterned coatings with static colors have previously been created by photocross-linking thermochromic oligomeric ChLC precursors to fix the color at different temperatures using photomasks ${ }^{43}$ or by painting ChLC polymer particles of different colors, ${ }^{31}$ with the latter example even presenting an irreversible color shift upon heating. However, a reversible thermochromic reflection band shift in a multicolor patterned ChLC coating has not been realized so far. The difficulty lies in

Received: October 21, 2021

Accepted: December 9, 2021

Published: December 22, 2021 
Scheme 1. (a) Components Used in the Coating Formulations and (b) Fabrication Scheme of the Patterned Responsive Photonic Coating Using Initiator 1

(a)

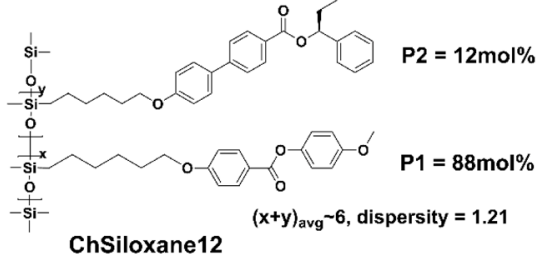

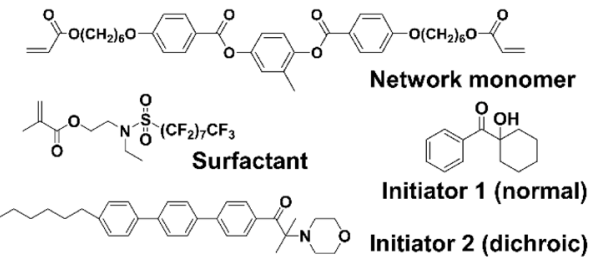

Initiator 2 (dichroic)

(b)

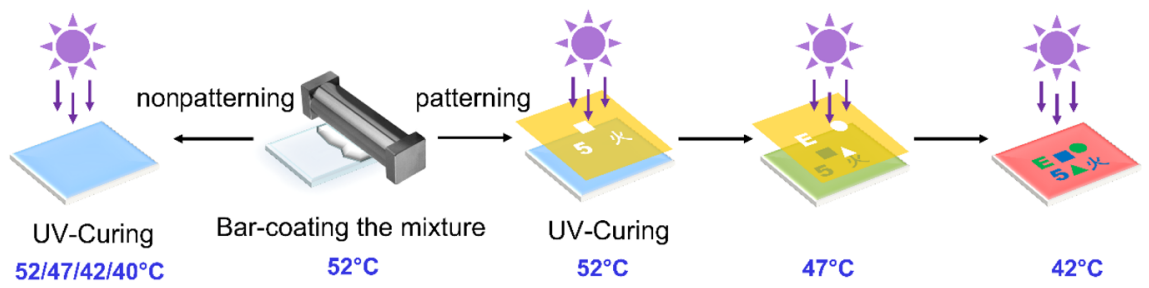

the conflicting roles of the cross-linked network: the mobility of the mesogens, which is required for a reversible response, is easily lost by cross-linking the material, but at the same time, the cross-linking is used to fix the helical pitches into different colors. $^{43,44}$ Although the printing of encapsulated ChLC droplets containing various ingredients might be viable, ${ }^{29,45}$ it would be more convenient if the thermochromic response can be manipulated within a single formulation. ${ }^{46}$ So far, the scientific challenge to fabricate thermochromic coatings with multicolor patterns remains. Linearly polarized light (LPL)dependent structural colors in ChLCs by deforming the circular helices into elliptical shapes ${ }^{47-51}$ have been reported using achiral oligosiloxane LCs and chiral network monomers ( $>15$ wt \%), which feature reflection color dependency of LPL with patternability. However, this system is also not thermochromic. $^{49}$

In this work, we show a thermochromic patterned coating consisting of ChLC siloxane oligomers (ChSiloxane12, Scheme 1a) stabilized by a diacrylate LC network. The ChLC siloxane possesses a thermochromic response originating from a smectic A-to-cholesteric $(\mathrm{Sm}-\mathrm{Ch})$ pretransitional effect. $^{38,52-55}$ Structural color patterns can be made via polymerization at different temperatures using photomasks, and a three-color patterned coating was fabricated for demonstration. Remarkably, when heated, each color has its own temperature shift onset, and the initially multicolored coating becomes a single color at higher temperatures. In addition, linearly polarized light dependency can be obtained, and these stratified thermochromic coatings show changing colors when altering the polarization angle of incident LPL. We created a stratified two-color patterned coating for demonstration of its potential toward aesthetics and security applications.

\section{EXPERIMENTAL SECTION}

Materials. The network monomer was purchased from Merck. The initiator 1 (Irgacure 184) was purchased from Ciba Specialty

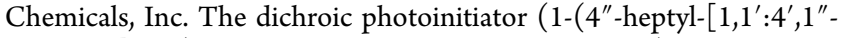
terphenyl]-4-yl)-2-methyl-2- morpholinopropan-1-one) was obtained from Merck. The surfactant (2-(N-ethylperfluorooctanesulfonamide) ethyl methacrylate) was purchased from Acros. The polyimide Optmer AL 1051 or alternatively AL 1254 was purchased from JSR Micro.
Synthesis. The cholesteric ChSiloxane12 was lab synthesized following literature methods and materials. ${ }^{38}$ The feed ratio of P1/P2 precursors in the reaction was adjusted to be $88 / 12$ in mol. Yield: $3.2192 \mathrm{~g}, 69.2 \%$.

${ }^{1} \mathrm{H}$ NMR $\left(400 \mathrm{MHz}, \mathrm{CDCl}_{3}\right): \delta 8.10,7.59,7.52,7.41,7.35,7.28$, 7.08, 6.91, 5.93, 3.99, 3.81, 2.07, 1.96, 1.79, 1.48, 1.45, 1.41, 0.97, $0.56,0.11,0.05$. The full NMR spectrum with peak assignments and integral values can be found in Figure S1. The average backbone length $(x+y)_{\text {avg }}$ calculated from NMR peak integrals was 6.0, based on the literature method. ${ }^{28}$

GPC (THF, detector: PDA-254 nm in polystyrene standards): $M_{\mathrm{n}}$ $=3534 \mathrm{Da}, M_{\mathrm{w}}=4295 \mathrm{Da}, M_{\mathrm{z}}=5173 \mathrm{Da}$, and $M_{\mathrm{w}} / M_{\mathrm{n}}=1.21$. The molecular distribution curve can be found in Figure S2.

Phase transitions of ChSiloxane12 were revealed by DSC: G-2 Sm 39.7 Ch 64.9 I. Full DSC traces can be found in Figure S3.

Preparation of ChLC Mixtures. In a tan glass vial were weighted ChSiloxane12 and the network monomers. The surfactant and the initiator were then added into the mixture via diluted toluene solution in volumetric flasks. More toluene was added to dissolve all the components homogeneously. The total solute comprised about $45 \mathrm{wt}$ $\%$ of the mixture.

The composition for nonstratified coatings was as follows: ChSiloxane12/network monomer/surfactant/initiator $1=94.6 / 4 / 1$ / 0.4 in weight ratio. The initiator 1 ratio in the mixture was lowered to 0.04 for the patterned, nonstratified coatings.

The composition for stratification was as follows: ChSiloxane12/ network monomer/surfactant/initiator $2=94 / 4 / 1 / 1$ in weight ratio.

Preparation of Rubbed Polyimide-Coated Glass Substrates. The glass substrates were of $9 \times 9 \mathrm{~cm}^{2}$ size, and the procedure of applying a polyimide layer followed the exact same method as reported in the previous study. ${ }^{49}$

Preparation of the Coatings. An RK PrintCoat Instruments K control coater was used to prepare all coatings. The example of nonstratified, nonpatterned coatings is given below: On a $9 \times 9 \mathrm{~cm}^{2}$ size glass substrate with rubbed polyimide was loaded $60 \mu \mathrm{L}$ of the mixture, and it was placed at $100{ }^{\circ} \mathrm{C}$ for $40 \mathrm{~min}$ to evaporate the solvent. Afterward, the substrate was transported to the preheated coater, at $52{ }^{\circ} \mathrm{C}$ on the substrate surface. The coating was applied using a $60 \mu \mathrm{m}$ gap (4-sided applicator, $1107 / 80 / 1$, Sheen), which was pushed forward over the mixture automatically by the coater. The speed of the applicator movement was about $0.5 \mathrm{~cm} / \mathrm{s}$ in the direction antiparallel to the rubbing direction of the polyimide layer. The coating was then cooled down to the desired temperature (recorded at the substrate surface) and was UV-cured using an EXFO Omnicure S2000 mercury lamp at an intensity of $4.5 \mathrm{~mW} / \mathrm{cm}^{2}$ (unpolarized) for $1 \mathrm{~min}$ in a nitrogen environment followed by postcuring for $4 \mathrm{~min}$. The coating was cooled to room temperature. The entire piece of coating was cut into several pieces for different tests using a glass 
(a)

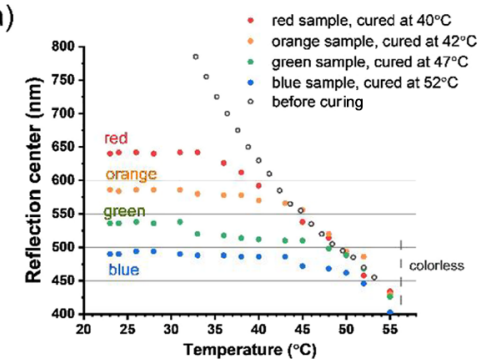

(b)

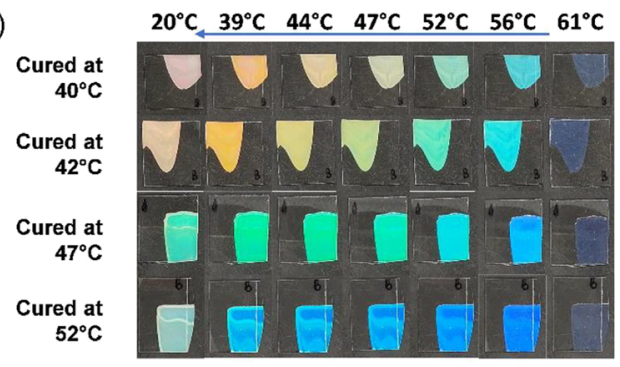

Figure 1. (a) Reflection center versus temperature of the coatings cured at $40,42,47$, and $52{ }^{\circ} \mathrm{C}$ during cooling, including a comparison to the uncured mixture. Slight variation in the central wavelength among the samples at the same temperature is expected, as the actual temperature during each test might deviate slightly from calibration. (b) Images of the cured coatings at different temperatures during cooling, from 61 to $20{ }^{\circ} \mathrm{C}$.

cutter. All optical measurements including photos of the coatings were started from the second cycle of heating-and-cooling between 20 and $61{ }^{\circ} \mathrm{C}$.

For the stratification process, a high-contrast linear polarizer (PUVD260C35S from LOT-QuantumDesign $\mathrm{GmbH}$ ) was placed between the coating and the UV light source during the curing. The polarization direction was perpendicular to the coating direction. The intensity of polarized UV light that reached the coating surface was $\sim 1.5 \mathrm{~mW} / \mathrm{cm}^{2}$.

For the patterned coatings, a photomask was placed above the coating during each temperature stage of UV curing (Scheme 1a). The photomasks were made from commercial polyimide tape (Kapton) stuck to glass plates and were laser-cut into different patterns. To avoid direct contact with the coating surface, the photomask was attached to the glass substrate using double-sided tape, whose thickness is larger but very close to the coating thickness.

The thickness of all obtained coatings was $22-27 \mu \mathrm{m}$ as determined by interferometry.

Characterizations. Proton nuclear magnetic resonance $\left({ }^{1} \mathrm{H}\right.$ NMR) spectra were recorded on a $400 \mathrm{MHz}$ Bruker Avance III HD spectrometer. Gel permeation chromatography (GPC) was performed on a Shimadzu LC-2030C.3D instrument equipped with a PDA-254 nm detector, using tetrahydrofuran (THF) as the eluent and monodisperse polystyrene calibration standards. Differential scanning calorimetry (DSC) curves were measured with a DSC Q2000, TA Instruments. Thicknesses of the coatings were examined using a Forgale Zoomsurf 3D interferometer.

Transmission spectra of unpolarized light were measured using a PerkinElmer LAMBDA $750 \mathrm{UV} /$ vis/NIR spectrophotometer with a $150 \mathrm{~mm}$ integrating sphere detector. Temperature control of the samples was realized via a Linkam THMS600 hot stage with a customized aperture diameter of $6 \mathrm{~mm}$. Heating and cooling of the hot stage were programmed using a Linkam T96 controller. For linearly polarized light transmission spectra and the polar plots, the spectrometer was equipped with a linear polarizer.

Transmission spectra of circular polarized light were measured on a Shimadzu UV-3102 PC equipped with a linear polarizer in combination with a quarter-wave plate.

Temperature calibrations for transmission spectra and the photographs followed the literature methods. ${ }^{38}$ Due to the differences in calibration methods and due to changes in the environmental temperature, a $1-3{ }^{\circ} \mathrm{C}$ difference in temperature designation among each test was expected.

\section{RESULTS AND DISCUSSION}

Thermochromic and Multicolor Pattern Coatings. Mixtures containing an oligosiloxane ChLC and a diacrylate LC monomer were prepared for the fabrication of thermochromic, multicolor patterned coatings (Scheme 1a). The siloxane random co-oligomer of mesogenic (P1) and chiral dopants (P2) was synthesized according to a literature method. ${ }^{56}$ The molar ratio of $\mathrm{P} 1 / \mathrm{P} 2$ is $88 / 12$, which is finetuned to make sure that the thermochromic response covers the full range of the visible part of the electromagnetic spectrum, where the shortest wavelength limit is decided by the content of P2. The average backbone length is found to be approximately 6 (Figure S1), with a polydispersity of 1.21 (Figure S2). The oligomer undergoes a ChLC-isotropic transition $\left(\mathrm{T}_{\mathrm{i}}\right)$ at $65{ }^{\circ} \mathrm{C}$, an $\mathrm{Sm}-\mathrm{Ch}$ transition $\left(\mathrm{T}_{\mathrm{Sm}-\mathrm{Ch}}\right)$ around $40{ }^{\circ} \mathrm{C}$, and a glass transition $\left(\mathrm{T}_{\mathrm{g}}\right)$ around $-2{ }^{\circ} \mathrm{C}$ (Figure S3). When brought into a planar alignment cell, strong thermochromic behavior can be observed within the cholesteric temperature range until becoming scattering near the end of the DSC transition peak, showing that the $\mathrm{Sm}-\mathrm{Ch}$ transition takes place (Figure S3). We chose the optimized network ratio of $4 \mathrm{wt} \%$, referring to the amount of diacrylate LC in the mixture, to prepare thermochromic photonic coatings. ${ }^{38}$ Furthermore, 1 wt \% methacrylate surfactant was added to the mixture to assist planar Ch alignment of the coating at the coating-air interface, as well as $0.4 \mathrm{wt} \%$ photoinitiator 1 to initiate network formation. Upon barcoating the mixture at $52{ }^{\circ} \mathrm{C}$ on a glass substrate with a rubbed polyimide layer, a planarly aligned cholesteric coating was obtained. The $\mathrm{Sm}-\mathrm{Ch}$ thermochromic response of the oligomer remains, showing blue $(470 \mathrm{~nm})$, green $(520 \mathrm{~nm})$, orange $(585 \mathrm{~nm})$, and red $(630 \mathrm{~nm})$ reflection at $52,47,42$, and $40{ }^{\circ} \mathrm{C}$, respectively (Figure 1a). Via subsequent polymerization of the diacrylate LC monomer under UV light irradiation at these temperatures, polymer-stabilized ChLC coatings are formed. We initially prepared individual singlecolor coatings cured at $52,47,42$, and $40{ }^{\circ} \mathrm{C}$, in order to investigate the thermochromic response of the different structural colors.

At room temperature (RT), the polymer-stabilized ChLC coating appears with blue, green, orange, and red color, respectively (Figure 1b). The slight scattering at room temperature can be explained by the formation of twisted smectic A domains, where the smectic order presents helical twists on the larger scale. ${ }^{38,55}$ A slightly longer reflection wavelength than in the uncured state is observed in the spectra due to the broader shape of the reflection bands (Figure 1a and Figure S4). This might be due to a certain degree of phase separation between the siloxane oligomer and the network. ${ }^{57}$ DSC curves of the cured coatings all reveal an isotropic transition peak around $63{ }^{\circ} \mathrm{C}$ and $\mathrm{Sm}-\mathrm{Ch}$ transitions around $39^{\circ} \mathrm{C}$, regardless of the curing temperature (Figure S5).

Heating and cooling cycles were performed on these coatings to examine their thermochromic responses. Cycles between $20(\mathrm{Sm})$ and $61{ }^{\circ} \mathrm{C}$ (isotropic) demonstrate a fully reversible thermochromic shift of these coatings, with each structural color showing its own unique thermochromic responsiveness (Figure 1 and Figure S6). For convenience, 


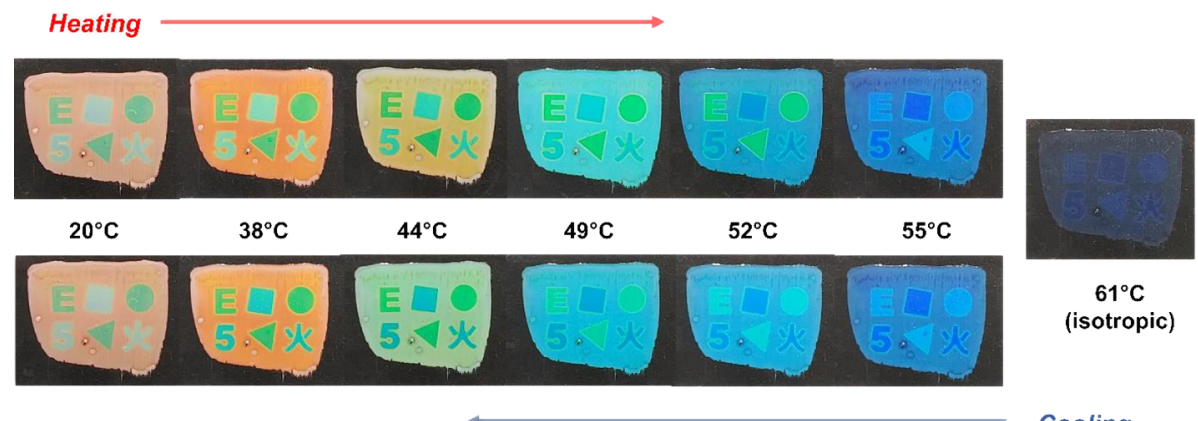

Figure 2. Images of the three-color patterned coating at various temperatures during heating and cooling between 20 and $61{ }^{\circ} \mathrm{C}$. The different areas were cured at different temperatures to generate the pattern. Each color of the pattern has a thermochromic response with a different onset temperature, with each reaching blue at $55{ }^{\circ} \mathrm{C}$.

Scheme 2. Schematic Presentation of the Stratification Process on ChLCs for the Fabrication of Patterned Thermochromic Coatings with LPL Dependency ${ }^{\mathrm{a}}$

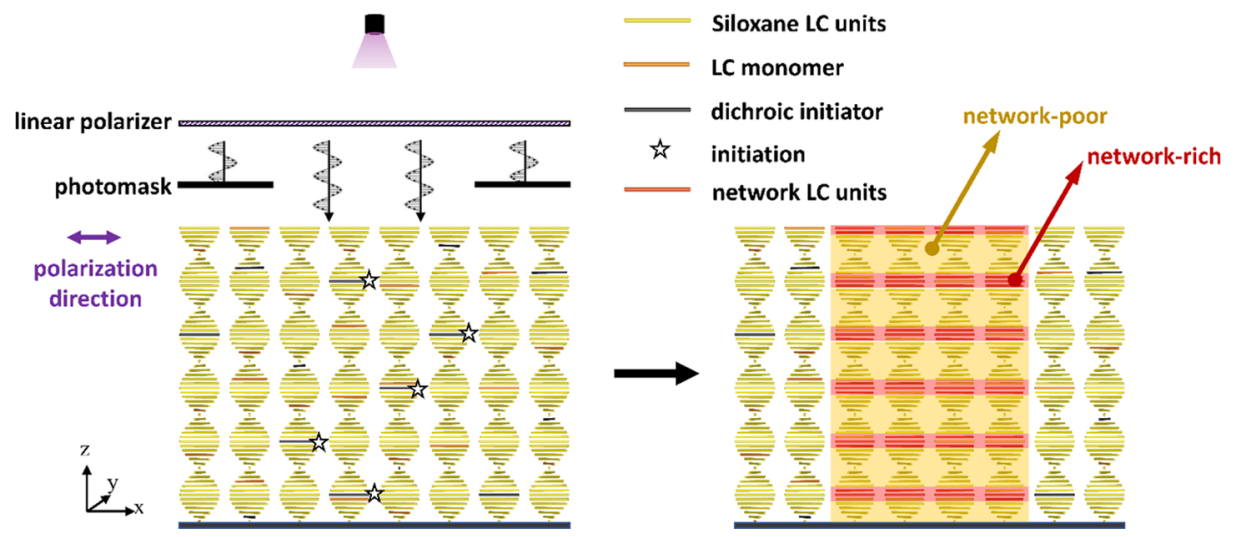

${ }^{a}$ Only the areas exposed to linearly polarized UV light are stratified, whereas the nonexposed areas maintain a regular chiral nematic helix.

we first discuss the cooling cycles. When cooling from 61 (isotropic) to $55{ }^{\circ} \mathrm{C}$ (cholesteric), a reflection band appears centered at 402-440 $\mathrm{nm}$ (blue) for all these samples. Therefore, the planar $\mathrm{Ch}$ alignment is not lost due to the memory of the liquid crystal network. When the samples are further cooled, the reflection color redshifts, following the same response as the uncured mixture until reaching the corresponding curing temperatures. Below that temperature, the shift versus temperature slows down and stalls at some point, except for the red sample, which starts to slow down at $42{ }^{\circ} \mathrm{C}$ and only stalls below $35^{\circ} \mathrm{C}$ (Figure 1a). Below $35^{\circ} \mathrm{C}$, upon entering the $\mathrm{Sm}$ phase, no further response of the band center is observed, but an increase in scattering takes place, thus sealing the plateau of the color shift at blue, green, orange, and red. It seems that the presence of the polymer network inhibits the pretransitional effect, which is present in the uncured mixture at lower temperatures. Interestingly, the RTred sample that was cured at $40^{\circ} \mathrm{C}$ has the largest color change $(\sim 210 \mathrm{~nm})$ changing from red to blue, while for the RT-blue sample cured at $52{ }^{\circ} \mathrm{C}$, the range is the smallest $(\sim 90 \mathrm{~nm}$, light blue to deep blue). During heating, the reverse thermochromic response is observed, reaching a blue reflection at $54{ }^{\circ} \mathrm{C}$ and showing disappearance of the color when heated further. However, the major band shift starts later than the curing temperature and has a steeper trend near $54{ }^{\circ} \mathrm{C}$ (Figure S7). This hysteresis is typical for polymer-stabilized liquid crystals having an $\mathrm{Sm}-\mathrm{Ch}$ phase transition. ${ }^{28,38,56}$ It is interesting that the reflection band shifts of these thermochromic coatings are stalling at higher temperatures than the Sm transition point. $^{28,38,56}$ In contrast, when using a lower network concentration ( $2 \mathrm{wt} \%$ ), the limit occurs at the Sm transition (Figure S8). It can be surmised that a higher density of the network generates a stronger anchoring effect ${ }^{58}$ to the mesogens that pushes the stalling temperature higher. Furthermore, it is beneficial to polymerize the cholesteric sample at a temperature that is not too close to the isotropic temperature to obtain a large color change.

Thermochromic color patterns are created via polymerization at different temperatures using photomasks (Scheme 1b). The photomasks were made from polyimide tape (Kapton), which has excellent absorption over the full UV range, via laser-cutting into different patterns. The RT-blue patterns were fabricated at $52{ }^{\circ} \mathrm{C}$ using a mask containing "square", "5", and "fire (in Chinese)" shapes, while the RTgreen patterns were created at $47{ }^{\circ} \mathrm{C}$ using a mask having "circle", "triangle", and "E" shapes. Finally, the RT-red background was polymerized at $40{ }^{\circ} \mathrm{C}$ to receive a threecolor pattern at room temperature (Figure 2). Upon increasing the temperature, the RT-red background changes color around $40{ }^{\circ} \mathrm{C}$, while the $\mathrm{RT}$-green and the $\mathrm{RT}$-blue patterns retain their colors until the steep blueshift above $52{ }^{\circ} \mathrm{C}$. At $55{ }^{\circ} \mathrm{C}$, just below the isotropic transition temperature, the background and the patterns appear in a blue color of different shades. Upon reaching the isotropic temperature at $61{ }^{\circ} \mathrm{C}$, the patterns turn mostly colorless with a slight purple reflection, which is assumed to originate from the polymer network mesogens. 
(a)

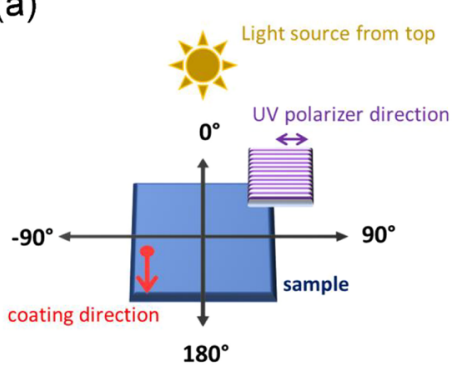

(c)

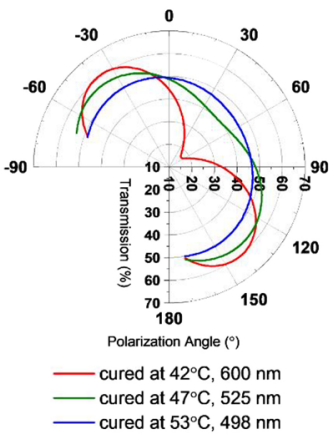

(b)

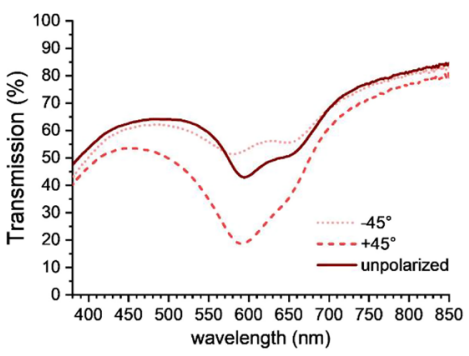

(d)

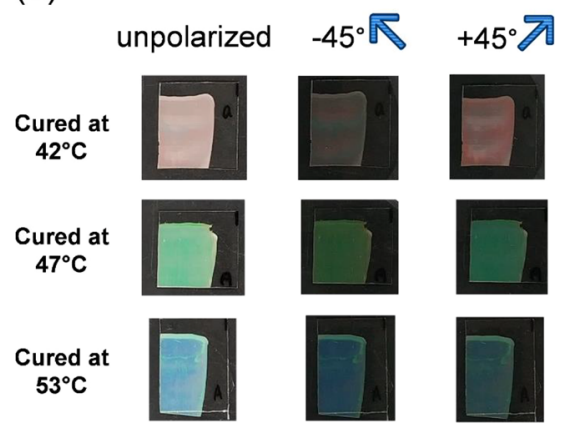

Figure 3. (a) Designation of linear polarization angles in the article, defining the direction of coating as $0 / 180^{\circ}$ and the $\mathrm{UV}$ light polarizer as $90^{\circ}$, when observed from the same side as the light source. (b) LPL-dependent transmission spectra of the stratified coating cured at $42{ }^{\circ} \mathrm{C}$ in the characteristic angles of -45 and $+45^{\circ}$, along with the unpolarized spectra at RT. (c) Polar plots of the transmission at the reflection band center wavelength of the stratified coatings cured at 42,47 , and $53{ }^{\circ} \mathrm{C}$, at room temperature. (d) Images of the stratified coatings at room temperature under unpolarized light and linearly polarized light at -45 and $+45^{\circ}$. The pictures were taken under the same lighting and camera conditions without postshot adjustments. A polarizer was mounted on top of the coating when taking polarized images.

The colors reappear with cooling from the isotropic, and the reversed thermochromic response of "square-5-fire", "circletriangle-E”, and the background is observed, until they settle in blue, green, and red at 52,47 , and $35{ }^{\circ} \mathrm{C}$, respectively. The thermochromic response in each part of the patterned coating's different areas is identical to the corresponding nonpatterned coatings.

Thermochromic Patterns with Light PolarizationDependent Color. We introduced LPL dependency features to our photonic coating by stratification using dichroic initiator 2 following our earlier reported method. ${ }^{49}$ The dichroic initiator aligns with the liquid crystal molecules and preferentially absorbs light with a polarization direction parallel to its molecular orientation (Scheme 2). As a result, when irradiated by linearly polarized UV, polymerization is initiated in the regions with the same molecular alignment director as the light polarization, which is every half a pitch length. The diacrylate network monomers are polymerized in these initiated regions, causing a diffusion of monomers from the noninitiated regions. The stratification process distorts the helical structures by local variation of the concentration of chiral molecules and forms alternating layers of network-rich and network-poor moieties with different refractive indices along the thickness.

The coating was polymerized with linearly polarized UV light with the polarization direction perpendicular to the coating direction, which from this point on is defined as $0 /$ $180^{\circ}$ (Figure 3a). When stratified at $42{ }^{\circ} \mathrm{C}$, a red reflecting coating is obtained at room temperature. The unpolarized transmission spectrum of the coating demonstrates an asymmetric reflection band centered at $600 \mathrm{~nm}$ with a minor notch at $650 \mathrm{~nm}$ (Figure $3 \mathrm{~b}$ ). Compared to the symmetric reflection band of the nonstratified sample cured at the same temperature, this asymmetric reflection band is broader and inclined to higher wavelengths (Figure S9), and therefore, its color at RT appears to be red (Figure 3d). Linearly polarized light transmission of $600 \mathrm{~nm}$ at varied polarization angles shows a "peanut-shaped" polar plot (Figure 3b,c, red curve). Transmission at $-45^{\circ}$ is the highest $(60 \%)$, while at $+45^{\circ}$ transmission is the lowest (17\%). The brightness contrast is clearly seen in photographic images under a linear polarizer, at the directions of -45 and $+45^{\circ}$ (Figure $3 \mathrm{~d}$ ). The transmission data also indicates a reflection of over $50 \%$ at $+45^{\circ}$ polarization, which exceeds the usual reflection limit of a single cholesteric layer. This is attributed to the distortion of the helices via stratification adding additional photonic effects. As the network-rich region is presumably achiral, there is an anisotropy of the refractive index between the $x$ and $y$ axis (Scheme 2). Such anisotropy could function as a retardation layer, which would transform LPL into circular polarized light (CPL). ${ }^{59,60}$ This would cause a decrease or increase of the transmission in the reflection band, depending on the handedness of transformed light. In our case, the transformed light could be ellipsoidal such that the reflection did not reach the $0 / 100 \%$ extremes. Apart from the brightness, the reflection color also slightly changes with the polarization angle due to the changed ratios of reflection band intensity between the two edges of the reflection band (Figure 3b). The RT-red coating retains high reflection of left-handed CPL, while also giving weak reflection of right-handed CPL (Figure S10). The reflected colors under right- and left-handed CPL are different as well.

RT-green and RT-blue samples were successfully prepared as well, via stratification at 47 and $53{ }^{\circ} \mathrm{C}$ (Figure 3d), where the uncured mixture appears in green and blue reflection, respectively. The reflection centers at RT in the unpolarized 
(a)

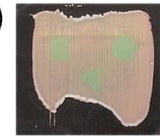

$20^{\circ} \mathrm{C}$ unpolarized

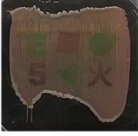

$\sqrt{ }-45^{\circ}$

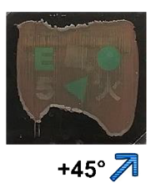

$+45^{\circ}$ 原 (b)

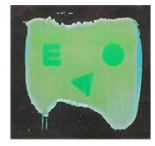

$46^{\circ} \mathrm{C}$ unpolarized

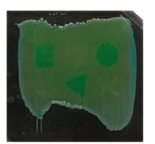

$\mathbb{R}-45^{\circ}$

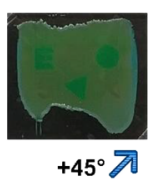

$+45^{\circ}$ 不

(c)

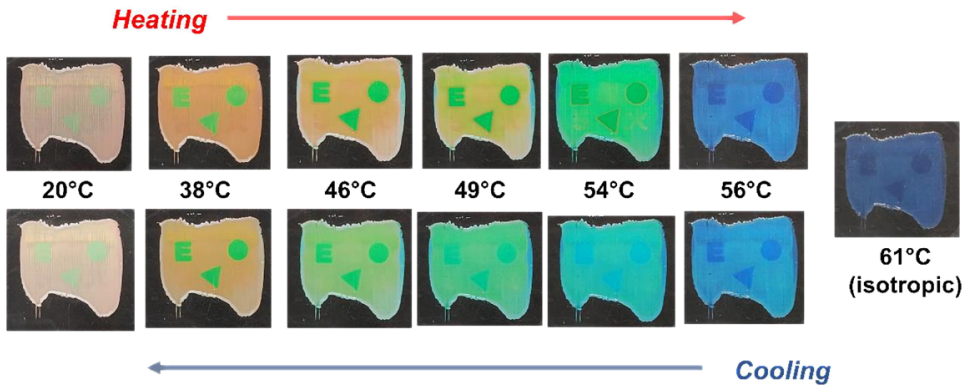

Figure 4. Images of the stratified patterned coating, showing (a) red and green patterns at room temperature. The red patterns, which were stratified, are hidden into the unstratified background of the same color under unpolarized light and are revealed under a linear polarizer. Both the stratified red and green patterns show variation in optics with rotating the polarization angle, between the darkest reflection angle of $-45^{\circ}$ and the brightest reflection angle of $+45^{\circ}$. (b) At an elevated temperature $\left(46^{\circ} \mathrm{C}\right)$, the angular dependency of the patterns is diminished. The hidden pattern is therefore not clearly revealed with a polarizer. (c) Thermochromic response of the coating at various temperatures during heating and cooling between 20 and $61{ }^{\circ} \mathrm{C}$, under unpolarized light.

spectra are at 525 and $498 \mathrm{~nm}$, respectively. However, the LPL angle dependencies of these samples are less prominent compared to the red sample (Figure $3 c$ and Figure S11). The lowest and highest transmissions of the green coating at its reflection center are 40 and $57 \%$, respectively, whereas for the blue coating, they are only 46 and $50 \%$, respectively. The LPL angular contrast of the RT-green sample is minor, and that of the RT-blue sample is hardly distinguishable by the naked eyes (Figure 3d). The angles showing the darkest and brightest reflection are still -45 and $+45^{\circ}$, respectively. We propose that proper stratification is more difficult to achieve for shorter pitches due to a shorter diffusion distance. As the distance between two initiated regions becomes shorter, less monomers are present within half a pitch, and thus, the gradient of network concentration is less between network-rich and network-poor regions, resulting in a reduced LPL dependency.

The stratified coatings present a similar type of thermochromic response compared to the unstratified coatings when viewed with unpolarized light. Major reflection band shifts start above the curing temperatures, and they are fully reversible upon cooling from isotropic (Figure S12). We investigated the LPL dependency at elevated temperatures as well. It is found that the LPL dependency of the RT-red and RT-green samples diminishes at temperatures higher than $35{ }^{\circ} \mathrm{C}$ but fully recovers when cooled to room temperature (Figure S13). The temperature at which LPL dependency disappears is around the $\mathrm{Sm}-\mathrm{Ch}$ transition of the coating. Therefore, it can be inferred that the LPL dependency is highly related to the smectic transition, in which the formed smectic clusters tend to align along the anisotropic direction of the network, extending the deformed areas in the helices.

A patterned coating with stratified structures was fabricated using the combination of a linear UV light polarizer and photomasks. The patterns of "circle", "triangle", and "E" were exposed at $47{ }^{\circ} \mathrm{C}$ (green color) with LP UV light; then, the patterns of "square", " 5 ", and "fire" were exposed at $42{ }^{\circ} \mathrm{C}$ (red color) with LP UV light, and finally, the background area was cured at $42{ }^{\circ} \mathrm{C}$ with unpolarized UV (Figure 4a). As the "square-5-fire" patterns were cured at the same temperature as the background, these patterns have almost the same color as the background and are therefore hidden with unpolarized light. The hidden red patterns can be clearly revealed under a linear polarizer due to the contrast in color and brightness against the unstratified background. Both the RT-red and RTgreen patterns show various shades of color when rotating the LPL direction between -45 and $+45^{\circ}$, with good resolution. At elevated temperatures where thermochromic shifts take place, the LPL dependency of both patterns is largely weakened, and the "square-5-fire patterns" are not clearly revealed by LPL anymore (Figure $4 \mathrm{~b}$ and Figure S14).

The coating shows diverse thermochromic response for the different colored patterns, in the same way compared to the unstratified coatings (Figure 4c). Throughout the temperature cycle, the RT-red patterns remained almost invisible under unpolarized light, proving the highly similar thermochromic response between stratified and unstratified parts. In particular, at $54{ }^{\circ} \mathrm{C}$ during cooling, all three parts show a uniform shade of the blue color, and therefore, all patterns are hidden. This is different from the unstratified patterns (Figure 2). We attribute this phenomenon to the broader reflection bands after stratification, whose reflection colors are more impure making it difficult to distinguish among different shades. At the isotropic temperature of $61^{\circ} \mathrm{C}$, the remaining blue color seems to be brighter than the unstratified patterns, which might be due to slight scattering in the sample. The stability of thermooptical performance is proven by repeatable results over three temperature cycles. As the hidden patterns could only be clearly revealed under a linear polarizer at room temperature, an interesting scenario of interactive art and information encryption by this patterned sample is presented.

\section{CONCLUSIONS}

We have developed thermochromic photonic coating devices that combine the features of patternability and LPL-dependent structural color. By performing polymerizations at different temperatures $\left(40-52{ }^{\circ} \mathrm{C}\right)$, various reflection colors from red to blue can be obtained. A three-color patterned coating could be prepared, and the initially multicolored coating becomes blue 
at higher temperatures, with each color shifting in sequence instead of all colors shifting simultaneously. Linear polarization-dependent color can be achieved, which shows color and brightness contrast of the reflection at room temperature when viewed with LPL between the polarization angles of -45 and $+45^{\circ}$. The LPL dependency mostly disappears at elevated temperatures, but this is fully reversible. We demonstrate an encrypted coating with some stratified patterns hidden into the unstratified background when viewed with unpolarized light at any temperature. The patterns are only revealed when viewed with LPL at room temperature. These multifunctional coatings would be of interest for products in aesthetics or security purposes. Protective topcoats could feasibly be applied to this ChLC coating to enhance the mechanical strength of the devices. $^{38,61,62}$

\section{ASSOCIATED CONTENT}

\section{SI Supporting Information}

The Supporting Information is available free of charge at https://pubs.acs.org/doi/10.1021/acsapm.1c01434.

Oligomer characterizations, detailed spectral measurements, and photos of the fabricated coatings (PDF)

\section{AUTHOR INFORMATION}

\section{Corresponding Authors}

Guofu Zhou - SCNU-TUE Joint Lab of Device Integrated Responsive Materials (DIRM), National Center for International Research on Green Optoelectronic and Guangdong Provincial Key Laboratory of Optical Information Materials and Technology \& Institute of Electronic Paper Displays, South China Academy of Advanced Optoelectronics, South China Normal University, Guangzhou 510006, China; Academy of Shenzhen Guohua Optoelectronics, Shenzhen 518110, China; o orcid.org/ 0000-0003-1101-1947; Email: guofu.zhou@m.scnu.edu.cn Laurens T. de Haan - SCNU-TUE Joint Lab of Device Integrated Responsive Materials (DIRM), National Center for International Research on Green Optoelectronic and Guangdong Provincial Key Laboratory of Optical Information Materials and Technology \& Institute of Electronic Paper Displays, South China Academy of Advanced Optoelectronics, South China Normal University, Guangzhou 510006, China; Laboratory of Stimuli-responsive Functional Materials \& Devices, Department of Chemical Engineering and Chemistry, Eindhoven University of Technology, 5600 MB Eindhoven, The Netherlands; (1) orcid.org/0000-0003-4978-1808; Phone: +86-0203931-4813; Email: 1dhaan@m.scnu.edu.cn

\section{Authors}

Weixin Zhang - SCNU-TUE Joint Lab of Device Integrated Responsive Materials (DIRM), National Center for International Research on Green Optoelectronic and Guangdong Provincial Key Laboratory of Optical Information Materials and Technology \& Institute of Electronic Paper Displays, South China Academy of Advanced Optoelectronics, South China Normal University, Guangzhou 510006, China; Laboratory of Stimuli-responsive Functional Materials \& Devices, Department of Chemical Engineering and Chemistry, Eindhoven University of Technology, 5600 MB Eindhoven, The Netherlands
Albertus P.H.J. Schenning - SCNU-TUE Joint Lab of Device Integrated Responsive Materials (DIRM), National Center for International Research on Green Optoelectronic, South China Normal University, Guangzhou 510006, China; Laboratory of Stimuli-responsive Functional Materials \& Devices, Department of Chemical Engineering and Chemistry, Eindhoven University of Technology, 5600 MB Eindhoven, The Netherlands; (1) orcid.org/0000-0002-3485-1984

Augustinus J.J. Kragt - SCNU-TUE Joint Lab of Device Integrated Responsive Materials (DIRM), National Center for International Research on Green Optoelectronic, South China Normal University, Guangzhou 510006, China; Laboratory of Stimuli-responsive Functional Materials \& Devices, Department of Chemical Engineering and Chemistry, Eindhoven University of Technology, $5600 \mathrm{MB}$ Eindhoven, The Netherlands; ClimAd Technology B.V., 6538 TE Nijmegen, The Netherlands

Complete contact information is available at: https://pubs.acs.org/10.1021/acsapm.1c01434

\section{Author Contributions}

W.Z. performed the investigation, methodology, visualization, and writing of the original draft; A.P.H.J.S. performed conceptualization, supervision, and review and editing of the manuscript; A.J.J.K. performed conceptualization and review and editing of the manuscript; G.Z. performed funding acquisition and project administration; L.T.d.H. performed conceptualization, supervision, and review and editing of the manuscript.

\section{Funding}

This work is supported by the National Key R\&D Program of China (2020YFE0100200), the Science and Technology Program of Guangzhou (grant no. 2019050001), the Program for Chang Jiang Scholars and Innovative Research Teams in Universities (no. IRT_17R40), the Guangdong Provincial Key Laboratory of Optical Information Materials and Technology (no. 2017B030301007), the MOE International Laboratory for Optical Information Technologies, and the 111 Project.

\section{Notes}

The authors declare no competing financial interest.

\section{ACKNOWLEDGMENTS}

We would like to thank Dr. Sebastian Fredrich for making the photomasks used in our experiments.

\section{REFERENCES}

(1) Wang, Y.; Runnerstrom, E. L.; Milliron, D. J. Switchable Materials for Smart Windows. Annu. Rev. Chem. Biomol. Eng. 2016, 7, 283-304.

(2) Sun, J.; Bhushan, B.; Tong, J. Structural Coloration in Nature. RSC Adv. 2013, 3, 14862.

(3) Barrera-Patiño, C. P.; Vollet-Filho, J. D.; Teixeira-Rosa, R. G.; Quiroz, H. P.; Dussan, A.; Inada, N. M.; Bagnato, V. S.; ReyGonzález, R. R. Photonic Effects in Natural Nanostructures on Morpho Cypris and Greta Oto Butterfly Wings. Sci. Rep. 2020, 10, 111.

(4) Dufresne, E. R.; Noh, H.; Saranathan, V.; Mochrie, S. G. J.; Cao, H.; Prum, R. O. Self-Assembly of Amorphous Biophotonic Nanostructures by Phase Separation. Soft Matter 2009, 5, 1792-1795.

(5) Yoshioka, S.; Kinoshita, S. Effect of Macroscopic Structure in Iridescent Color of the Peacock Feathers. Forma 2002, 17, 169-181. 
(6) Sharma, V.; Crne, M.; Park, J. O.; Srinivasarao, M. Structural Origin of Circularly Polarized Iridescence in Jeweled Beetles. Science 2009, 325, 449-451.

(7) Fernández Del Río, L.; Arwin, H.; Järrendahl, K. Polarizing Properties and Structural Characteristics of the Cuticle of the Scarab Beetle Chrysina Gloriosa. Thin Solid Films 2014, 571, 410-415.

(8) Teyssier, J.; Saenko, S. V.; Van Der Marel, D.; Milinkovitch, M. C. Photonic Crystals Cause Active Colour Change in Chameleons. Nat. Commun. 2015, 6, 1-7.

(9) Seeboth, A.; Lötzsch, D.; Ruhmann, R.; Muehling, O. Thermochromic Polymers-Function by Design. Chem. Rev. 2014, 114, 3037-3068.

(10) Van Heeswijk, E. P. A.; Kragt, A. J. J.; Grossiord, N.; Schenning, A. P. H. J. Environmentally Responsive Photonic Polymers. Chem. Commun. 2019, 55, 2880-2891.

(11) Ge, J.; Yin, Y. Responsive Photonic Crystals. Angew. Chem., Int. Ed. 2011, 50, 1492-1522.

(12) Wu, P.; Wang, J.; Jiang, L. Bio-Inspired Photonic Crystal Patterns. Mater. Horiz. 2020, 7, 338-365.

(13) Yang, J.; Zhao, W.; Yang, Z.; He, W.; Wang, J.; Ikeda, T.; Jiang, L. Printable Photonic Polymer Coating Based on a Monodomain Blue Phase Liquid Crystal Network. J. Mater. Chem. C 2019, 7, 1376413769.

(14) Yang, J.; Zhao, W.; Yang, Z.; He, W.; Wang, J.; Ikeda, T.; Jiang, L. Photonic Shape Memory Polymer Based on Liquid Crystalline Blue Phase Films. ACS Appl. Mater. Interfaces 2019, 11, 46124-46131.

(15) Qin, L.; Wei, J.; Yu, Y. Photostationary RGB Selective Reflection from Self-Organized Helical Superstructures for Continuous Photopatterning. Adv. Opt. Mater. 2019, 7, 1-7.

(16) Wan, H.; Li, X.; Zhang, L.; Li, X.; Liu, P.; Jiang, Z.; Yu, Z. Z. Rapidly Responsive and Flexible Chiral Nematic Cellulose Nanocrystal Composites as Multifunctional Rewritable Photonic Papers with Eco-Friendly Inks. ACS Appl. Mater. Interfaces 2018, 10, 59185925.

(17) Anyfantakis, M.; Jampani, V. S. R.; Kizhakidathazhath, R.; Binks, B. P.; Lagerwall, J. P. F. Responsive Photonic Liquid Marbles. Angew. Chem., Int. Ed. 2020, 59, 19260-19267.

(18) Hou, J.; Li, M.; Song, Y. Patterned Colloidal Photonic Crystals. Angew. Chem., Int. Ed. 2018, 57, 2544-2553.

(19) Bisoyi, H. K.; Bunning, T. J.; Li, Q. Stimuli-Driven Control of the Helical Axis of Self-Organized Soft Helical Superstructures. Adv. Mater. 2018, 30, 1706512.

(20) Sage, I. Thermochromic Liquid Crystals. Liq. Cryst. 2011, 38, $1551-1561$

(21) Wu, X.; Rodríguez-Gallegos, F. L.; Heep, M.-C.; Schwind, B.; Li, G.; Fabritius, H.; Freymann, G.; Förstner, J. Polarization Conversion Effect in Biological and Synthetic Photonic Diamond Structures. Adv. Opt. Mater. 2018, 6, 1800635.

(22) Ryabchun, A.; Sakhno, O.; Stumpe, J.; Bobrovsky, A. FullPolymer Cholesteric Composites for Transmission and Reflection Holographic Gratings. Adv. Opt. Mater. 2017, 5, 1-10.

(23) Dolan, J. A.; Wilts, B. D.; Vignolini, S.; Baumberg, J. J.; Steiner, U.; Wilkinson, T. D. Optical Properties of Gyroid Structured Materials: From Photonic Crystals to Metamaterials. Adv. Opt. Mater. 2015, 3, 12-32.

(24) Zhang, W.; Froyen, A. A. F.; Schenning, A. P. H. J.; Zhou, G.; Debije, M. G.; de Haan, L. T. Temperature-Responsive Photonic Devices Based on Cholesteric Liquid Crystals. Adv. Photonics Res. 2021, 2, 2100016

(25) Beeckman, J. Liquid-Crystal Photonic Applications. Opt. Eng. 2011, 50, No. 081202.

(26) Wang, L.; Urbas, A. M.; Li, Q. Nature-Inspired Emerging Chiral Liquid Crystal Nanostructures: From Molecular Self-Assembly to DNA Mesophase and Nanocolloids. Adv. Mater. 2020, 32, 1-42.

(27) Khandelwal, H.; van Heeswijk, E. P. A.; Schenning, A. P. H. J.; Debije, M. G. Paintable Temperature-Responsive Cholesteric Liquid Crystal Reflectors Encapsulated on a Single Flexible Polymer Substrate. J. Mater. Chem. C 2019, 7, 7395-7398.
(28) Zhang, W.; Kragt, S.; Schenning, A. P. H. J.; de Haan, L. T.; Zhou, G. Easily Processable Temperature-Responsive InfraredReflective Polymer Coatings. ACS Omega 2017, 2, 3475-3482.

(29) Yang, C.; Wu, B.; Ruan, J.; Zhao, P.; Chen, L.; Chen, D.; Ye, F. 3D-Printed Biomimetic Systems with Synergetic Color and Shape Responses Based on Oblate Cholesteric Liquid Crystal Droplets. Adv. Mater. 2021, 33, 2006361.

(30) Herzer, N.; Guneysu, H.; Davies, D. J. D.; Yildirim, D.; Vaccaro, A. R.; Broer, D. J.; Bastiaansen, C. W. M.; Schenning, A. P. H. J. Printable Optical Sensors Based on H-Bonded Supramolecular Cholesteric Liquid Crystal Networks. J. Am. Chem. Soc. 2012, 134, 7608-7611.

(31) Belmonte, A.; Pilz da Cunha, M.; Nickmans, K.; Schenning, A. P. H. J. Brush-Paintable, Temperature and Light Responsive Triple Shape-Memory Photonic Coatings Based on Micrometer-Sized Cholesteric Liquid Crystal Polymer Particles. Adv. Opt. Mater. 2020, 8, 2000054.

(32) Van Heeswijk, E. P. A.; Kloos, J. J. H.; Grossiord, N.; Schenning, A. P. H. J. Humidity-Gated, Temperature-Responsive Photonic Infrared Reflective Broadband Coatings. J. Mater. Chem. A 2019, 7, 6113-6119.

(33) Brannum, M. T.; Steele, A. M.; Venetos, M. C.; Korley, L. S. T. J.; Wnek, G. E.; White, T. J. Light Control with Liquid Crystalline Elastomers. Adv. Opt. Mater. 2019, 7, 1801683.

(34) Foelen, Y.; Van Der Heijden, D. A. C.; Del Pozo, M.; Lub, J.; Bastiaansen, C. W. M.; Schenning, A. P. H. J. An Optical Steam Sterilization Sensor Based on a Dual-Responsive Supramolecular Cross-Linked Photonic Polymer. ACS Appl. Mater. Interfaces 2020, 12, 16896-16902.

(35) Scarangella, A.; Soldan, V.; Mitov, M. Biomimetic Design of Iridescent Insect Cuticles with Tailored, Self-Organized Cholesteric Patterns. Nat. Commun. 2020, 11, 4108.

(36) Kragt, A. J. J.; Zuurbier, N. C. M.; Broer, D. J.; Schenning, A. P. H. J. Temperature-Responsive, Multicolor-Changing Photonic Polymers. ACS Appl. Mater. Interfaces 2019, 11, 28172-28179.

(37) Moirangthem, M.; Engels, T. A. P.; Murphy, J.; Bastiaansen, C. W. M.; Schenning, A. P. H. J. Photonic Shape Memory Polymer with Stable Multiple Colors. ACS Appl. Mater. Interfaces 2017, 9, 3216132167 .

(38) Zhang, W.; Schenning, A. P. H. J.; Kragt, A. J. J.; Zhou, G.; de Haan, L. T. Reversible Thermochromic Photonic Coatings with a Protective Topcoat. ACS Appl. Mater. Interfaces 2021, 13, 3153-3160.

(39) Chen, F.; Guo, J.; Qu, Z.; Wei, J. Novel Photo-Polymerizable Chiral Hydrogen-Bonded Self-Assembled Complexes: Preparation, Characterization and the Utilization as a Thermal Switching Reflective Color Film. J. Mater. Chem. 2011, 21, 8574-8582.

(40) Moirangthem, M.; Stumpel, J. E.; Alp, B.; Teunissen, P.; Bastiaansen, C. W. M.; Schenning, A. P. H. J. Hot Pen and Laser Writable Photonic Polymer Films. In Proc. SPIE 9769, Emerging Liquid Crystal Technologies XI; Spie-Int Soc Optical Engineering: San Francisco, CA, 2016; Vol. 9769, p 97690Y.

(41) van Heeswijk, E. P. A.; Meerman, T.; de Heer, J.; Grossiord, N.; Schenning, A. P. H. J. Paintable Encapsulated Body-TemperatureResponsive Photonic Reflectors with Arbitrary Shapes. ACS Appl. Polym. Mater. 2019, 1, 3407-3412.

(42) Ranjkesh, A.; Yoon, T.-H. Fabrication of a Single-Substrate Flexible Thermoresponsive Cholesteric Liquid-Crystal Film with Wavelength Tunability. ACS Appl. Mater. Interfaces 2019, 11, 26314-26322.

(43) Zhang, P.; Kragt, A. J. J.; Schenning, A. P. H. J.; De Haan, L. T.; Zhou, G. An Easily Coatable Temperature Responsive Cholesteric Liquid Crystal Oligomer for Making Structural Colour Patterns. J. Mater. Chem. C 2018, 6, 7184-7187.

(44) Zhang, L.; Wang, M.; Wang, L.; Yang, D. K.; Yu, H.; Yang, H. Polymeric Infrared Reflective Thin Films with Ultra-Broad Bandwidth. Liq. Cryst. 2016, 43, 750-757.

(45) Lee, S. S.; Kim, J. B.; Kim, Y. H.; Kim, S.-H. WavelengthTunable and Shape-Reconfigurable Photonic Capsule Resonators 
Containing Cholesteric Liquid Crystals. Sci. Adv. 2018, 4, No. eaat8276.

(46) Zheng, Z. G.; Lu, Y. Q.; Li, Q. Photoprogrammable Mesogenic Soft Helical Architectures: A Promising Avenue toward Future ChiroOptics. Adv. Mater. 2020, 32, 1-19.

(47) Zhang, P.; Zhou, G.; de Haan, L. T.; Schenning, A. P. H. J. 4D Chiral Photonic Actuators with Switchable Hyper-Reflectivity. Adv. Funct. Mater. 2021, 31, 2007887.

(48) Bourgerette, C.; Chen, B.; Finkelmann, H.; Mitov, M.; Schmidtke, J.; Stille, W. Variation of the Network Anisotropy of Cholesteric Side Chain Elastomers. Macromolecules 2006, 39, 81638170 .

(49) Kragt, A. J. J.; Hoekstra, D. C.; Stallinga, S.; Broer, D. J.; Schenning, A. P. H. J. 3D Helix Engineering in Chiral Photonic Materials. Adv. Mater. 2019, 31, 1903120.

(50) Broer, D. J. Deformed Chiral-Nematic Networks Obtained by Polarized Excitation of a Dichroic Photoinitiator. Curr. Opin. Solid State Mater. Sci. 2002, 6, 553-561.

(51) Serrano-Ramón, B.; Kjellander, C.; Zakerhamidi, S.; Bastiaansen, C. W. M.; Broer, D. J. 3D-Structured Liquid Crystal Networks Formed by Dichroic Photoinitiator Initiated Photopolymerization. Emerg. Liq. Cryst. Technol. III 2008, 6911, 691109.

(52) Tzeng, S. Y. T.; Chen, C. N.; Tzeng, Y. Thermal Tuning Band Gap in Cholesteric Liquid Crystals. Liq. Cryst. 2010, 37, 1221-1224.

(53) Natarajan, L. V.; Wofford, J. M.; Tondiglia, V. P.; Sutherland, R. L.; Koerner, H.; Vaia, R. A.; Bunning, T. J. Electro-Thermal Tuning in a Negative Dielectric Cholesteric Liquid Crystal Material. J. Appl. Phys. 2008, 103, No. 093107.

(54) Chilaya, G. S. Effect of Various External Factors and Pretransitional Phenomena on Structural Transformations in Cholesteric Liquid Crystals. Crystallogr. Reports 2000, 45, 871-886.

(55) Dhar, R. Twisted-Grain-Boundary (TGB) Phases: Nanostructured Liquid-Crystal Analogue of Abrikosov Vortex Lattices. Phase Transitions 2006, 79, 175-199.

(56) Zhang, W.; Lub, J.; Schenning, A. P. H. J.; Zhou, G.; de Haan, L. T. Polymer Stabilized Cholesteric Liquid Crystal Siloxane for Temperature-Responsive Photonic Coatings. Int. J. Mol. Sci. 2020, 21, 1803.

(57) Dierking, I.; Kosbar, L. L.; Lowe, A. C.; Held, G. A. Polymer Network Structure and Electro-Optic Performance of Polymer Stabilized Cholesteric Textures I. The Influence of Curing Temperature. Liq. Cryst. 1998, 24, 387-395.

(58) Yuan, X.; Zhang, L.; Yang, H. Study of Selectively Reflecting Characteristics of Polymer Stabilised Chiral Nematic Liquid Crystal Films with a Temperature-Dependent Pitch Length. Liq. Cryst. 2010, 37, 445-451.

(59) Yamamoto, M.; Endo, K.; Kuwana, Y.; Nishiyama, I. SingleLayered Retardation Films with Negative Wavelength Dispersion Birefringence Made from Liquid-Crystalline Monomers. J. Soc. Inf. Disp. 2017, 25, 405-410.

(60) Mulcahy, S.; Parri, O.; Saito, I. 40-1: Invited Paper: New Liquid Crystal and Reactive Mesogens Mixtures for Passive and Active Photonic Components. SID Symp. Dig. Tech. Pap. 2021, 52, 550-552.

(61) Govers, S. P. W.; Alexander, N.; Al-Masri, M.; Omeis, J.; vander Ven, L. G. J.; de With, G.; Esteves, A. C. C. Surface Segregation of Polydimethylsiloxane-Polyether Block Copolymers in Coatings Driven by Molecular Architecture. Prog. Org. Coatings 2021, 150, 105991.

(62) RepelFlex® _ NBD Nano https://www.nbdnano.com/ solutions/coatings/repelflex/ (accessed 2021-04 -26).

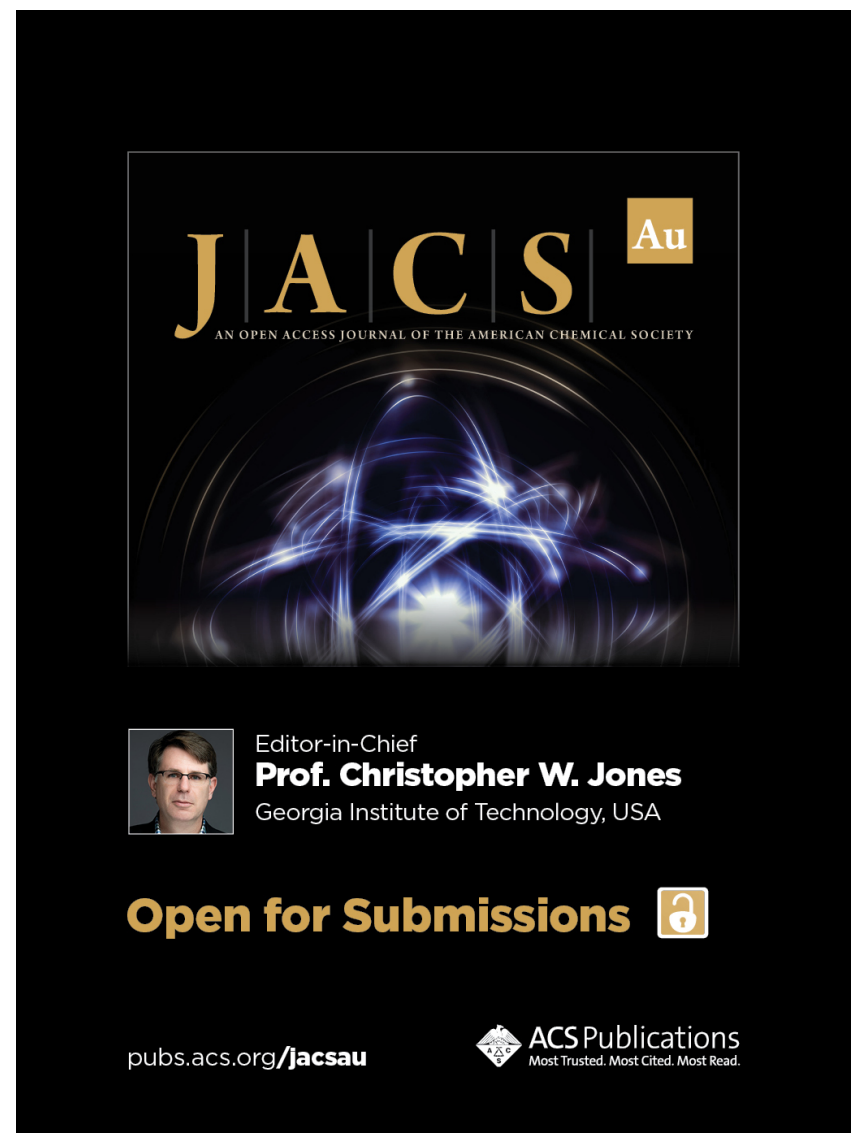

